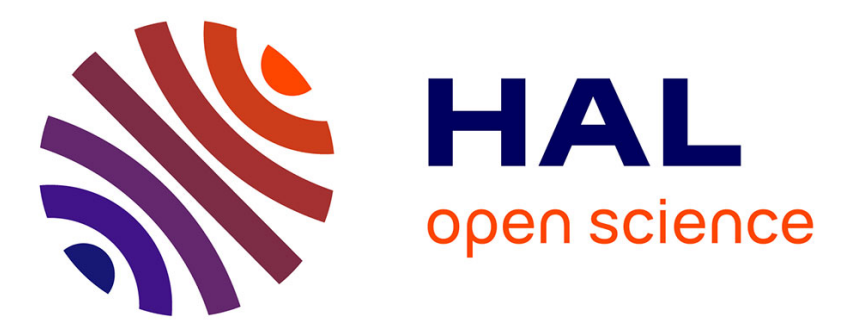

\title{
Host and adsorbate dynamics in silicates with flexible frameworks: Empirical force field simulation of water in silicalite
}

Patrice Bordat, Pierre-André Cazade, Isabelle Baraille, Ross Brown

\section{- To cite this version:}

Patrice Bordat, Pierre-André Cazade, Isabelle Baraille, Ross Brown. Host and adsorbate dynamics in silicates with flexible frameworks: Empirical force field simulation of water in silicalite. Journal of Chemical Physics, 2010, 132, pp.094501/1-094501/8. 10.1063/1.3314286 . hal-03225305

\section{HAL Id: hal-03225305 \\ https: / hal-univ-pau.archives-ouvertes.fr/hal-03225305}

Submitted on 12 May 2021

HAL is a multi-disciplinary open access archive for the deposit and dissemination of scientific research documents, whether they are published or not. The documents may come from teaching and research institutions in France or abroad, or from public or private research centers.
L'archive ouverte pluridisciplinaire $\mathbf{H A L}$, est destinée au dépôt et à la diffusion de documents scientifiques de niveau recherche, publiés ou non, émanant des établissements d'enseignement et de recherche français ou étrangers, des laboratoires publics ou privés. 


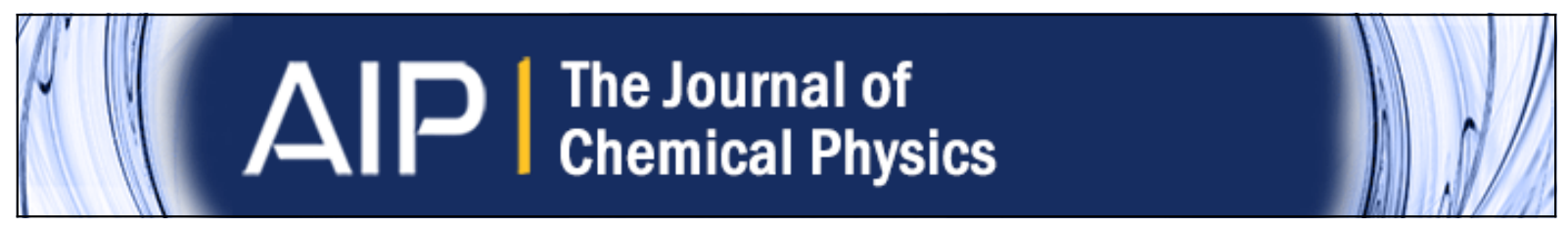

\section{Host and adsorbate dynamics in silicates with flexible frameworks: Empirical force field simulation of water in silicalite}

Patrice Bordat, Pierre-André Cazade, Isabelle Baraille, and Ross Brown

Citation: The Journal of Chemical Physics 132, 094501 (2010); doi: 10.1063/1.3314286

View online: http://dx.doi.org/10.1063/1.3314286

View Table of Contents: http://scitation.aip.org/content/aip/journal/jcp/132/9?ver=pdfcov

Published by the AIP Publishing

\section{Articles you may be interested in}

Communication: Evidence of structural phase transitions in silicalite-1 by infrared spectroscopy

J. Chem. Phys. 139, 091103 (2013); 10.1063/1.4819080

Molecular dynamics study of free energy of transfer of alcohol and amine from water phase to the micelle by thermodynamic integration method

J. Chem. Phys. 137, 094902 (2012); 10.1063/1.4747491

Dynamical behavior of one-dimensional water molecule chains in zeolites: Nanosecond time-scale molecular dynamics simulations of bikitaite

J. Chem. Phys. 120, 9233 (2004); 10.1063/1.1697382

Interfaces between silicalite surfaces and liquid hexadecane: A molecular dynamics simulation

J. Chem. Phys. 116, 6311 (2002); 10.1063/1.1457447

Electric-field-dependent empirical potentials for molecules and crystals: A first application to flexible water molecule adsorbed in zeolites

J. Chem. Phys. 112, 8267 (2000); 10.1063/1.481432

How can you REACH $100 \%$

of researchers at the Top 100

Physical Sciences Universities?

With The Journal of Chemical Physics.

AIP $\left.\right|_{\text {Chemical Physics }} ^{\text {The Journal of }}$

THERE'S POWER IN NUMBERS. Reach the world with AIP Publishing.

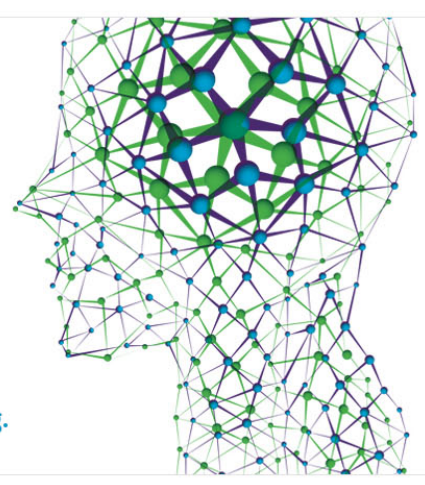




\title{
Host and adsorbate dynamics in silicates with flexible frameworks: Empirical force field simulation of water in silicalite
}

\author{
Patrice Bordat, Pierre-André Cazade, Isabelle Baraille, and Ross Brown ${ }^{\text {a) }}$ \\ Institut pluridisciplinaire de recherche sur l'environnement et les matériaux, UMR 5254 du C.N.R.S. et de \\ l'Université de Pau et des pays de l'Adour, avenue Pierre Angot, Pau Cedex 64053, France
}

(Received 18 December 2009; accepted 16 January 2010; published online 2 March 2010)

\begin{abstract}
Molecular dynamics simulations are performed on the pure silica zeolite silicalite (MFI framework code), maintaining via a new force field both framework flexibility and realistic account of electrostatic interactions with adsorbed water. The force field is similar to the well-known "BKS" model [B. W. H. van Beest et al., Phys. Rev. Lett. 64, 1955 (1990)], but with reduced partial atomic charges and reoptimized covalent bond potential wells. The present force field reproduces the monoclinic to orthorhombic transition of silicalite. The force field correctly represents the hydrophobicity of pure silica silicalite, both the adsorption energy, and the molecular diffusion constants of water. Two types of adsorption, specific and weak unspecific, are predicted on the channel walls and at the channel intersection. We discuss molecular diffusion of water in silicalite, deducing a barrier to crossing between the straight and the zigzag channels. Analysis of the thermal motion shows that at room temperature, framework oxygen atoms incurring into the zeolite channels significantly influence the dynamics of adsorbed water. (c) 2010 American Institute of Physics.

[doi:10.1063/1.3314286]
\end{abstract}

\section{INTRODUCTION}

While silicas are among the chemically simplest of minerals, their structure and dynamics are fascinatingly rich and varied, thanks in part to the subtle interplay of the rigidity of the $\mathrm{SiO}_{4}$ units and to the flexibility introduced by their association in networks of corner- or edge-sharing tetrahedra. Rigid body (librational) modes of the tetrahedra ${ }^{1}$ are well known illustrations of this diversity. The balance of forces in porous polymorphs such as zeolites is even more delicate, so that their phase transitions may depend on the presence of defects $^{2}$ or of occluded molecules, as when adsorption of p-xylene in H-ZSM-5 stabilizes the orthorhombic phase. ${ }^{3}$

Surprisingly, although framework flexibility has long been suspected to be an important parameter in problems of molecular adsorption and diffusion in zeolites, ${ }^{4}$ most simulations of adsorption assume rigid frameworks. Smit et al. ${ }^{5}$ suggested that "breathing" of the channels between pores may influence diffusion when the channel diameter closely matches the size of the guest molecule. Demontis et al. ${ }^{6}$ observed an increase in the calculated diffusion constant of water in hydrophobic silicalite, from $6.6 \times 10^{-5}$ to 8.6 $\times 10^{-5} \mathrm{~cm}^{2} \mathrm{~s}^{-1}$, between models with a rigid and a flexible framework. However, it is difficult to draw general conclusions. A very recent study by Zimmermann et al $^{7}$ concluded that the question is complex and that no clear-cut general answer can be made.

The reverse side of the coin has received even less attention: Although the flexibility of zeolite frameworks often leads to several solid phases, the influence of occluded material on the flexibility and on the phase transitions has not

\footnotetext{
${ }^{a)}$ Author to whom correspondence should be addressed. Electronic mail: ross.brown@univ-pau.fr.
}

been explored widely in simulations. This may be due in part to the difficulty of accurately modeling the guest-host interactions, which are rather small compared to the strong ionocovalent forces within the framework. In order to understand the problem, we must briefly recall the nature of common force fields for oxide minerals.

A number of highly successful force fields have been developed for classical molecular dynamics or Monte Carlo (MC) simulations of silicates, ${ }^{8-12}$ aluminosilicates, ${ }^{13,9,10,14,15}$ and aluminophosphates. ${ }^{9,16-18}$ Most force fields for oxide materials are of the Born-Mayers-Huggins type, comprising Buckingham, Morse or other potential wells, representing the covalent part of the bonds and Coulomb interactions between atomic charges, representing the partial ionic character. These interactions act on any pair of atoms that happen to be close enough to each other. Sometimes bond angles are improved by introducing screened three body terms. ${ }^{13}$

While such force fields are very satisfactory for simulating many properties of oxide materials, it should be noted that they often exaggerate the ionic character of the chemical bonds by assuming large partial atomic charges. For example, formal atomic charges, e.g., $q_{\mathrm{Si}}=+4, q_{\mathrm{O}}=-2$ (in units of electronic charge), have been applied widely to silicas, aluminosilicates and aluminophosphates. ${ }^{13,19,17}$ Even in models of silica with partial atomic charges, ${ }^{8,12,9}$ one typically finds $q_{\mathrm{Si}} \geq 2$.

There are several indications that these charges are too large for straightforward use when simulating adsorption. For example, linear combination of atomic orbitals (LCAO)-HF calculations on $\alpha$-quartz lead to Mulliken charges $q_{\mathrm{Si}}$ between 1.40 (Refs. 20 and 21) and 1.49 (Refs. 22 and 23$)\left(q_{\mathrm{O}}=-0.7\right.$ to -0.75$)$. We performed similar calculations on $\alpha$-cristobalite with the LCAO-B3LYP 
formalism with CRYSTAL06, ${ }^{24,25}$ obtaining $q_{\mathrm{Si}}=1.78 \quad\left(q_{\mathrm{O}}\right.$ $=-0.89){ }^{26}$

Problems may occur also when occluded molecules are adsorbed at the mineral surface because the charges in force fields for minerals are much larger than those assigned to atoms in typical molecular force fields, which usually are less than 0.5 and mostly in the range of $0-0.2$. It is thus easy to overestimate the Coulomb forces between the guest and the mineral host. Of course, one could restrict electrostatics to only the framework or to the guest material or drop them from the framework-guest interaction. But this is not physically acceptable, except for very simple adsorbates, such as rare gas atoms, ${ }^{27}$ since electrostatics may play a significant role in orienting the molecules relative to the surface or pore. It is also technically impossible or difficult in many molecular dynamics programs. Use of appropriate reduced charges is important too in QM/MM simulations. ${ }^{28}$

Alternatively, one can seek to reduce the charges on the mineral moitey, which should improve the description of interactions with the organic adsorbates. But that simultaneously perturbs the model of the mineral, typically leading to collapse of the structure. One is thus led further to freeze the mineral host, e.g., at its experimental geometry. This approximation may be reasonable for the surface of a dense material, but as noted above, neglects interesting influences of the organic phase on the host framework itself. Desbiens and co-workers ${ }^{23,29}$ estimated the adsorption isotherms of water in silicalite from grand canonical MC (GCMC) simulations in which the host was frozen and its charges reduced sufficiently to prevent condensation of water in the pores at pressures below the saturated vapor pressure of water, which ensures hydrophobicity. These authors conclude that $q_{\mathrm{Si}}$ should not exceed 1.7, in agreement with the GCMC simulations and quantum calculations of Ramachandran et al. ${ }^{30}$ Molecular dynamics simulations in similar conditions then provide diffusion constants of water in the range of $3.3-8.8 \times 10^{-5} \mathrm{~cm}^{2} \mathrm{~s}^{-1}$ at $298 \mathrm{~K}$ (Refs. 31 and 32) and $6.7-10.5 \times 10^{-5} \mathrm{~cm}^{2} \mathrm{~s}^{-1}$ at $393 \mathrm{~K}^{33}$ greater than for liquid water $\left(2.3 \times 10^{-5} \mathrm{~cm}^{2} \mathrm{~s}^{-1}\right),{ }^{33,34}$ again pointing to the weak bonding between water and silicalite.

There is thus a need for force fields for flexible metal oxide frameworks, with partial charges compatible with standard force-fields for common organics, such as the OPLS all atom force field. ${ }^{35}$ The pioneering force field of Demontis et al. ${ }^{6}$ with $q_{\mathrm{Si}}=+2$ provides a satisfactory adsorption energy for water in silicalite, $-32.5 \mathrm{~kJ} \mathrm{~mol}^{-1}$, well within the experimental range (from -25 to $-50 \mathrm{~kJ} \mathrm{~mol}^{-1}$ ) and a reasonable diffusion constant. However, it appears to us difficult to implement in standard molecular dynamics codes. We therefore feel that there is a need for a simple Born-MayerHuggins type model of silica with reduced charges consistent with quantum chemical calculations and with data on the adsorption of water and allowing for full flexibility of zeolite frameworks.

In this paper we present a force field for silica with partial charges $q_{\mathrm{Si}}=+1.6$ and $q_{\mathrm{O}}=-0.8$. This force field accounts rather well for the structural and elastic properties of several bulk silica polymorphs. It also provides a good model of silicalite, reproducing both the structure of the framework
TABLE I. Structural and elastic properties of $\alpha$-quartz. Experimental values at low temperature and results of energy minimizations with the original and the modified BKS models.

\begin{tabular}{lccc}
\hline \hline & & $\mathrm{BKS}$ & $\mathrm{BKS}$ \\
& Exp. & $q_{\mathrm{Si}}=+2.4$ & $q_{\mathrm{Si}}=+1.6$ \\
\hline$a^{\text {a }}$ & 4.9021 & 4.920 & 4.921 \\
$c(\AA)$ & 5.3997 & 5.442 & 5.397 \\
$\gamma^{\mathrm{b}}\left(^{\circ}\right)$ & 120 & 120 & 120 \\
$\mathrm{u}^{\mathrm{c}}$ & 0.468 & 0.463 & 0.468 \\
$\mathrm{Si}-\mathrm{O}(\AA)$ & 1.583 & 1.587 & 1.592 \\
$\mathrm{Si}-\mathrm{O}-\mathrm{Si}\left(^{\circ}\right)$ & 143.2 & 144.1 & 143.7 \\
$\mathrm{O}-\mathrm{Si}-\mathrm{O}\left(^{\circ}\right)$ & 108.9 & 107.7 & 108.4 \\
$C_{11}{ }^{\mathrm{d}}$ & 87.26 & 88.5 & 92.2 \\
$C_{33}$ & 109.19 & 112.4 & 108.7 \\
$C_{44}$ & 59.72 & 51.2 & 56.0 \\
$C_{66}(\mathrm{GPa})$ & 38.68 & 39.4 & 40.0 \\
$C_{12}$ & 9.9 & 9.6 & 12.2 \\
$C_{13}$ & 13.02 & 16.5 & 19.6 \\
$C_{14}$ & -17.73 & -17.0 & -12.4 \\
\hline
\end{tabular}

${ }^{\mathrm{a}}$ Experimental data at $10 \mathrm{~K}$ from Ref. 41.

${ }^{\mathrm{b}}$ Space group constrained to $P 3_{1} 21$.

${ }^{\mathrm{c}} \mathrm{Si}$ lies on $(u, u, 1 / 3)$.

${ }^{\mathrm{d}}$ Experimental data at $77 \mathrm{~K}$ from Ref. 42.

and its monoclinic to orthorhombic transition. When combined with the SPC/E model of water, ${ }^{38,39}$ the model also reproduces the important result that pure unhydroxylated silica is hydrophobic. Such a force field should be useful for simulation of adsorption in zeolites and for studying the fascinating influence of occluded organic molecules on the structure and dynamics of the host framework.

\section{FORCE FIELD OPTIMIZATION}

Our starting point for a force field with reduced charges was the BKS model of silica of van Beest et al. ${ }^{9}$ This model has partial charges $q_{\mathrm{Si}}=+2.4, q_{\mathrm{O}}=-1.2$, and 6-exp potential wells between $\mathrm{Si}-\mathrm{O}$ and $\mathrm{O}-\mathrm{O}$ pairs

$$
V_{i j}(r)=A_{i j} \exp \left(-B_{i j} r\right)-C_{i j} / r^{6}, \quad \text { for } \quad i, j=\mathrm{Si}, \mathrm{O} \text {. }
$$

There are no three body terms. The parameters were in part derived from $a b$ initio calculations on small clusters capped with hydrogens. Those authors found that reasonable agreement with the $a b$ initio data could be achieved over a rather wide range of atomic charges. The final charges and the well parameters were determined by comparing lattice energy minimizations for $\alpha$-quartz with experimental data on the unit cell and elastic constants. Despite its rather simple form and although the $a b$ initio calculations would today be considered rather low level, the BKS force field performs very well and is widely used. For example, the discontinuity between force-field simulations and Car-Parinello molecular dynamics (CPMD) simulations of a model of amorphous silica was very small. ${ }^{36}$ Table I shows the properties of $\alpha$-quartz simulated here with this model, in energy minimizations with the GULP code. ${ }^{37}$ 
TABLE II. Force field parameters for SPC/E water in silicalite (BKS model).

\begin{tabular}{lccccc}
\hline \hline & $\mathrm{Si}$ & $\mathrm{O}$ & $\mathrm{OW}$ & $\mathrm{HW}$ & \\
\hline$q_{i}(e)$ & +2.4 & -1.2 & -0.8476 & +0.4238 & \\
& Buckingham & $A(\mathrm{eV})$ & $B\left(\AA^{-1}\right)$ & $C\left(\mathrm{eV} \AA^{6}\right)$ & $D\left(\mathrm{eV} \AA^{40}\right)$ \\
\hline $\mathrm{O}-\mathrm{O}$ & 1388.8 & 2.760 & 175.00 & $10^{6}$ \\
$\mathrm{Si-O}$ & 18003.8 & 4.873 & 133.54 & 80 \\
& & $\sigma(\AA)$ & $\varepsilon\left(10^{-3} \mathrm{eV} \mathrm{mol}^{-1}\right)$ & & \\
\hline OW-OW & & 3.166 & 6.737 & & \\
O-OW & & 3.166 & 6.737 & & \\
\hline \hline
\end{tabular}

\section{A. Range of framework partial charges compatible with hydrophobicity}

In order to determine how much it would be necessary to reduce the charges on the framework atoms, we first examined the dynamics of a single water molecule in a model silicalite host crystal of $2 \times 2 \times 3$ unit cells, represented by the standard BKS model. Water was represented by the SPC/E model. ${ }^{38,39}$ Besides electrostatic interactions between water and the framework, we included repulsion-dispersion terms between the framework oxygen atoms, $\mathrm{O}$, and the water oxygen atom, OW. Neglecting adsorbate interaction with the cations is a long standing approximation corresponding to the greater dispersion interactions (polarizability) of the anion and to its protrusion into the zeolite channels. ${ }^{40}$ It may be observed that the 6-exp O-O potential in the BKS model happens to be quite close to the Lennard-Jones potential between oxygens in SPC/E water. Considering the overall similarities of the situations of oxygen in silica and in a water molecule, and the similarity of the estimated partial charges in silica (see Sec. I) and the model charge in water $\left(q_{\mathrm{OW}}=\right.$ -0.8476 ), we approximate the $\mathrm{O}-\mathrm{OW}$ interactions by the corresponding OW-OW terms in the SPC/E model. Table II provides all the parameters of the model. The energy of adsorption of water in silicalite determined with the above model is $-67 \mathrm{~kJ} \mathrm{~mol}^{-1}$, making the zeolite extremely hydrophilic, contrary to experiment.

The next step is to determine the range of the charge on silicon, $q_{\mathrm{Si}}$, consistent with hydrophobicity of silicalite, by computing the energy of adsorption as a function of $q_{\mathrm{Si}}$. In line with the discussion in Sec. I, in order to vary the charges on the framework, one would normally have to freeze it. Here, we use instead a facility in DL_POLY ${ }^{43}$ to in effect reduce or screen the framework charges seen by water, while keeping them at their full values in the BKS force field as far as the dynamics of the framework is concerned. The framework can thus be kept flexible. Instead of defining the 6-exp part of the BKS force field in the standard input in the usual way, DL_POLY can be made to read in from file arbitrary pair interactions. Using this facility we can add to the required 6-exp functions between say framework oxygen, $\mathrm{O}$, and water oxygen, OW, screening potentials of the form $\delta q / 4 \pi \epsilon_{0} r$ between framework and water atoms. Thus, the adsorbed water experiences the electrostatic field of reduced charges on the framework atoms, while the framework itself continues to experience the full interactions specified in the BKS force field. This is not quite correct since the Coulomb interactions between explicitly defined charges are evaluated with the Ewald approximation, whereas the screening terms are not, but the method suffices to determine the order of magnitude of the adsorption energy with reduced charges.

We performed simulated annealing to determine the average adsorption energy for $q_{\mathrm{Si}}$ in the range of $2.4 \rightarrow 0$ (with $2 q_{\mathrm{O}}=-q_{\mathrm{Si}}$ ), until the framework became hydrophobic. Simulated annealing was performed in the NPT ensemble with a time step of $1 \mathrm{fs}$ and with Ewald summation for electrostatic interactions (200 cycles of heating to $T=300 \mathrm{~K}$ over 2 $\times 10^{3}$ steps and of cooling to $T=1 \mathrm{~K}$ over $10^{4}$ steps). Hydrophobicity was defined as when (a) the adsorption energy fell below the enthalpy of vaporization of the model of liquid water; and (b) the water molecule began to diffuse freely in the channels of the zeolite. Figure 1 shows that the framework is hydrophobic for $q_{\mathrm{Si}}<1.6$. This partial charge is also consistent with the Mulliken charges in periodic $a b$ initio calculations on $\alpha$-quartz, performed with a reoptimized basis in the CRYSTAL code, where $q_{\mathrm{Si}}<1.78$ for a variety of methods. ${ }^{26}$

\section{B. Parameter optimization}

Our aim is now to reduce the partial atomic charges in the BKS model, adjusting the 6-exp potential wells at each step to preserve the modeled properties of $\alpha$-quartz. There are six 6-exp parameters to be fitted for each value of $q_{\mathrm{Si}}$. We used 11 observables: the lattice parameters $a$ and $c$, the fractional coordinates of oxygen and silicon [silicon lies on

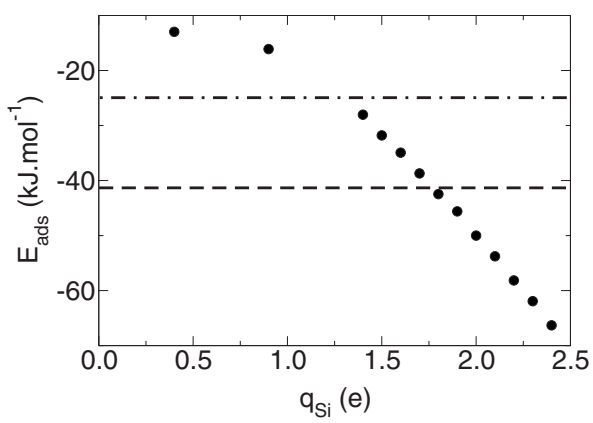

FIG. 1. Adsorption energy of SPC/E water in silicalite, as a function of the partial charge on silicon. The framework is hydrophobic for $q_{\mathrm{Si}}<1$.6. The dashed and the dot-dashed lines show, respectively, the vaporization enthalpy of the SPC/E model of water (Ref. 39) and the smallest experimental adsorption energy of water in silicalite (Ref. 6). 
TABLE III. BKS ${ }^{\text {mod }}$ silica force field parameters.

\begin{tabular}{lcccrr}
\hline \hline Interaction & $A$ & $B$ & $C$ & $D$ \\
$(\mathrm{eV})$ & $\left(\AA^{-1}\right)$ & $\left(\mathrm{eV} \AA^{6}\right)$ & $\begin{array}{r}q_{i} \\
(e)\end{array}$ \\
\hline $\mathrm{O}-\mathrm{O}$ & 1134.34 & 2.742 & 106.45 & 1517746.8 & $-0.8(\mathrm{O})$ \\
$\mathrm{Si}-\mathrm{O}$ & 16424.81 & 4.914 & 136.06 & 1951.39 & $1.6(\mathrm{Si})$ \\
\hline
\end{tabular}

$(u, u, 1 / 3)]$, and the elastic constants $C_{11}, C_{33}, C_{44}, C_{66}, C_{12}$, and $C_{14}$. We chose not to fit the elastic constant $C_{13}$, since it is the only one not well reproduced by the work of van Beest et $a l^{9}{ }^{9}$ and the reported experimental value might possibly be in error. Ideally, one should optimize the parameters by performing molecular dynamics simulations at the temperature at which the experimental data were recorded. Fortunately, data on the structure ${ }^{41}$ and elastic constants ${ }^{42}$ of $\alpha$-quartz are available for 13 and $77 \mathrm{~K}$, respectively, and may be compared with energy minimizations. We therefore minimized the potential energy and calculated the elastic constants from the Hessian, using the GULP code. ${ }^{37}$ The cutoff in real space for the Ewald summation of interactions was $12 \AA$. The space group was constrained to $P 3_{1} 21$, but we checked at every stage that all eigenvalues of the Hessian were positive, except for the lowest three, which were accurately vanishing. This procedure was pursued by 0.1 steps from $q_{\mathrm{Si}}=+2.4$ down to $q_{\mathrm{Si}}=0$.

\section{Optimized force field}

Like van Beest et al., ${ }^{9}$ we found that the quality of the simulated properties was insensitive to the value of $q_{\mathrm{Si}}$. Below, we use the 6-exp parameters determined for $q_{\mathrm{Si}}=+1.6$ (Table III force field "BKS ${ }^{\text {mod"), }}$, which corresponds to the onset of hydrophobicity in Fig. 1. Figure 2 compares the initial (BKS, $\left.q_{\mathrm{Si}}=+2.4\right)$ and final $\left(q_{\mathrm{Si}}=+1.6\right)$ potential wells. The reduced charges in the new model compared to BKS are compensated by a deeper $\mathrm{Si}-\mathrm{O}$ well, with a minimum necessarily closer to the desired experimental equilibrium bond length. The simulated properties at the beginning and the end of the optimization procedure are provided for convenience in Table I. While not quite as good as the initial BKS model, agreement with the data on $\alpha$-quartz remains acceptable throughout the reduction in the partial charges. It should be pointed out that the sum of the electrostatic and 6-exp terms

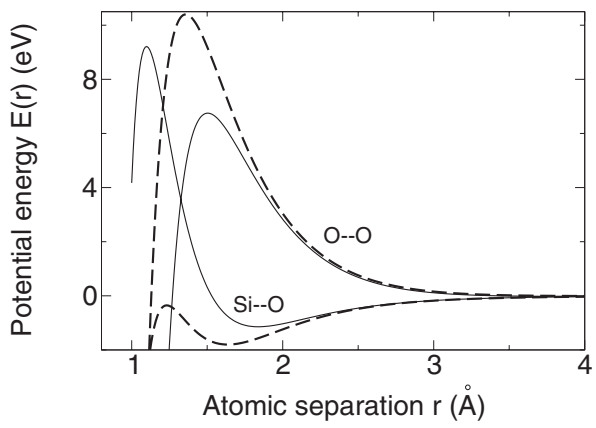

FIG. 2. 6-exp potential wells in the BKS model (Ref. 9) (thin lines) and optimized here for $q_{\mathrm{Si}}=+1.6$ (thick lines). The well-known " $r \rightarrow 0$ " catastrophe of 6-exp functions (Ref. 36), visible at the left of the figure, can be suppressed if necessary by addition of an appropriate term $D / r^{n}$ where $D$ $>0$ and $n \gg 6$. for an individual $\mathrm{Si}-\mathrm{O}$ bond does not present a well defined minimum, but merely a shoulder at $r_{\mathrm{Si}-\mathrm{O}} \approx 1.4 \AA$, implying that the model is unsuitable for simulating silica glass by quenching from the melt.

\section{APPLICATION TO SILICA POLYMORPHS}

In what follows, all molecular dynamics simulations were performed with the DL_POLY code, ${ }^{43}$ with periodic boundary conditions, a time step of $1 \mathrm{fs}$ and coupling time constants to the Berendsen thermo ${ }^{44}$ and isostress barostats, ${ }^{43}$ of 0.1 and $0.5 \mathrm{ps}$, respectively. Short range interactions were cut off at $10 \AA$ and Ewald summation was used for the electrostatic interactions.

\section{A. Cristobalite}

As a first test of the transferability of the new force field, we examined cristobalite. Once again, data are available for very low temperatures, see Table IV. There is also a phase transition at $523 \mathrm{~K}$ discussed in detail by Peacor. ${ }^{45}$ Cristobalite was optimized analytically here at constant symmetry, from both the room temperature and the low temperature data, with identical results.

The BKS and $\mathrm{BKS}^{\mathrm{mod}}$ force fields are of comparable quality, their main shortcoming for $\alpha$-cristobalite being the $c$ cell parameter, which is too small, particularly for BKS ${ }^{\text {mod }}$ (see Table IV). As for $\alpha$-quartz, systematically larger elastic constants are obtained with the BKS ${ }^{\text {mod }}$ model. Anharmonicity (our calculations being done $T=0 \mathrm{~K}$ ) is expected to contribute to values greater than those obtained with the BKS model by Kimizuka and Kaburaki ${ }^{46}$ in simulations at room temperature. The discrepancy in the sign of $C_{13}$ is also due to determining elastic constants for minimized models (low temperature phase), whereas the experimental data were recorded close to the auxetic transition, in which stretching (compression) in one direction is accompanied by a perpendicular expansion (shrinking). Figure 3 shows the temperature dependence of the simulated cell volume of cristobalite. There is a small but clear jump in the cell volume at $1400 \mathrm{~K}$. The same change was found on cooling (data not shown). The structure of $\beta$-cristobalite in the high temperature phase is identified as a cubic structure in agreement with experiment.

\section{B. Silicalite}

Silicalite undergoes a monoclinic to orthorhombic transition at a temperature dependent on the aluminum content. Pure silica silicalite is orthorhombic at room temperature. The transition was located at $340 \mathrm{~K}$ in H-ZSM-5. ${ }^{47,2} \mathrm{Using}$ GULP, we optimized the structure with the $\mathrm{BKS}^{\text {mod }}$ force field, at constrained symmetry, starting from the experimen- 
TABLE IV. Experimental and simulated properties of $\alpha$-cristobalite.

\begin{tabular}{|c|c|c|c|c|c|}
\hline & $\begin{array}{l}\text { Exp. }^{\mathrm{a}} \\
(301 \mathrm{~K})\end{array}$ & $\begin{array}{l}\mathrm{BKS}^{\mathrm{mod}} \\
(300 \mathrm{~K})\end{array}$ & $\begin{array}{l}\text { Exp. }^{\text {b }} \\
(10 \mathrm{~K})\end{array}$ & $\begin{array}{l}\text { BKS } \\
(0 \mathrm{~K})\end{array}$ & $\begin{array}{c}\mathrm{BKS}^{\mathrm{mod}} \\
(0 \mathrm{~K})\end{array}$ \\
\hline$a(\AA)$ & 4.9787 & 4.898 & 4.9570 & 4.906 & 4.873 \\
\hline$c(\AA)$ & 6.9502 & 6.459 & 6.8903 & 6.568 & 6.394 \\
\hline \multicolumn{6}{|l|}{$\mathrm{Si}$} \\
\hline$x$ & 0.3002 & 0.3190 & 0.3047 & 0.3233 & 0.3220 \\
\hline \multicolumn{6}{|l|}{$\mathrm{O}$} \\
\hline$x$ & 0.2381 & 0.2339 & 0.2381 & 0.2346 & 0.2326 \\
\hline$y$ & 0.1109 & 0.1300 & 0.1109 & 0.1317 & 0.1355 \\
\hline$z$ & 0.1826 & 0.1917 & 0.1826 & 0.1872 & 0.1948 \\
\hline $\mathrm{Si}-\mathrm{O}(\AA)$ & 1.605 & 1.602 & 1.617 & 1.601 & 1.602 \\
\hline $\mathrm{Si}-\mathrm{O}-\mathrm{Si}\left({ }^{\circ}\right)$ & 146.4 & 141.2 & 144.7 & 143.2 & 139.7 \\
\hline $\mathrm{O}-\mathrm{Si}-\mathrm{O}\left({ }^{\circ}\right)$ & 108.0 & 109.5 & 109.9 & 109.5 & 109.8 \\
\hline (GPa) & $\begin{array}{l}\text { Exp. }^{\mathrm{c}} \\
(300 \mathrm{~K})\end{array}$ & $\begin{array}{l}\text { TTAM }^{\mathrm{d}} \\
(300 \mathrm{~K})\end{array}$ & $\begin{array}{c}\mathrm{BKS}^{\mathrm{d}} \\
(300 \mathrm{~K})\end{array}$ & $\begin{array}{l}\text { BKS } \\
(0 \mathrm{~K})\end{array}$ & $\begin{array}{c}\mathrm{BKS}^{\mathrm{mod}} \\
(0 \mathrm{~K})\end{array}$ \\
\hline$C_{11}$ & 59.4 & 48.1 & 64.5 & 68.2 & 86.0 \\
\hline$C_{33}$ & 42.4 & 35.3 & 37.9 & 44.9 & 53.4 \\
\hline$C_{44}$ & 67.2 & 57.8 & 69.5 & 71.7 & 64.8 \\
\hline$C_{66}$ & 25.7 & 19.8 & 27.6 & 25.0 & 31.3 \\
\hline$C_{12}$ & 3.8 & 5.6 & 6.5 & 10.6 & 20.5 \\
\hline$C_{13}$ & -4.4 & -4.2 & -0.7 & 1.8 & 10.7 \\
\hline
\end{tabular}

${ }^{\mathrm{a}}$ Reference 45.

${ }^{\mathrm{b}}$ Reference 56.

${ }^{\mathrm{c}}$ Reference 57.

${ }^{\mathrm{d}}$ Reference 46.

tal structures at room temperature (orthorhombic ${ }^{47,2}$ ) and at low temperature (monoclinic ${ }^{47,2}$ ). In agreement with experiment, the monoclinic form $\left(\beta=91^{\circ}\right)$ is found to be the more stable (by $42.4 \mathrm{~kJ} \mathrm{~mol}^{-1}$ per unit cell). The cell parameters (see Table V) compare well with experimental values ${ }^{47,2}$ In a series of runs at increasing temperatures, this model nicely showed the transition to orthorhombic symmetry, at about $150 \mathrm{~K}$, see Fig. 4. The most stable form with the original BKS model is also monoclinic, but we did not locate the transition in simulations up to $2000 \mathrm{~K}$.

In view of the interest in zeolite framework dynamics, ${ }^{1}$ it is worthwhile examining the thermal motion of the host material. We calculated the thermal ellipsoids of all framework atoms. As expected and similar to our results on cristobalite (data not shown), thermal motion is well described by rigid body motion of the $\mathrm{SiO}_{4}$ tetrahedra. Thus, the thermal motion of silicon atoms is nearly spherical. Oxygen atoms on the other hand, show lenticular ellipsoids flattened along the

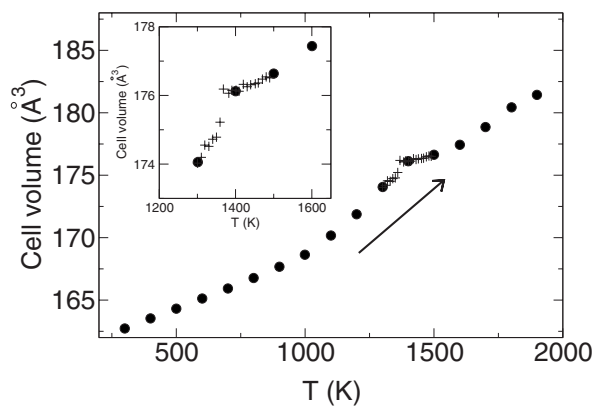

FIG. 3. Simulated temperature dependence of the cell volume of cristobalite (arrow shows order of simulations).
$\mathrm{Si}-\mathrm{O}$ bond directions. This observation and comparisons of the simultaneous fluctuations of $\mathrm{O}-\mathrm{O}$ and $\mathrm{Si}-\mathrm{O}$ distances within tetrahedra confirm as expected that thermal motion is principally translation and rotation of the tetrahedra.

A more interesting observation is that motion of oxygens lining the zeolite channels tends to be perpendicular to the channel. This is illustrated in Fig. 5, which shows the directions of the principal axes of those ellipsoids where the principal axis exceeds the secondary axes by a factor of 1.5 or more. Examining the fluctuations of a pairs of orthogonal diameters $(\mathrm{O}-\mathrm{O}$ distance) in the straight channel, we found weakly anticorrelated variations of rms amplitude $0.24 \AA$ with a characteristic time scale of $1.3 \mathrm{ps}$ (peak at $20 \mathrm{~cm}^{-1}$ in the power spectrum).

\section{Hydrophobicity of silicalite}

Strong calcination of silica to drive off all surface hydroxyl groups is known to produce a hydrophobic material which initially does not uptake atmospheric water. ${ }^{48}$ Experi-

TABLE V. Unit cell parameters of silicalite obtained in unconstrained minimizations, starting from the orthorhombic and the monoclinic structures.

\begin{tabular}{lcc}
\hline \hline & $\mathrm{BKS}^{\text {mod }}, P_{\text {nma }}$ & $\mathrm{BKS}^{\text {mod }}, P 2_{1 / a}$ \\
\hline$a(\AA)$ & 19.66 & 19.56 \\
$b(\AA)$ & 19.58 & 19.70 \\
$c(\AA)$ & 13.25 & 13.36 \\
$\alpha\left({ }^{\circ}\right)$ & 90.2 & 90.1 \\
$\beta\left({ }^{\circ}\right)$ & 89.9 & 91.3 \\
$\gamma\left({ }^{\circ}\right)$ & 90.1 & 90.1 \\
\hline \hline
\end{tabular}



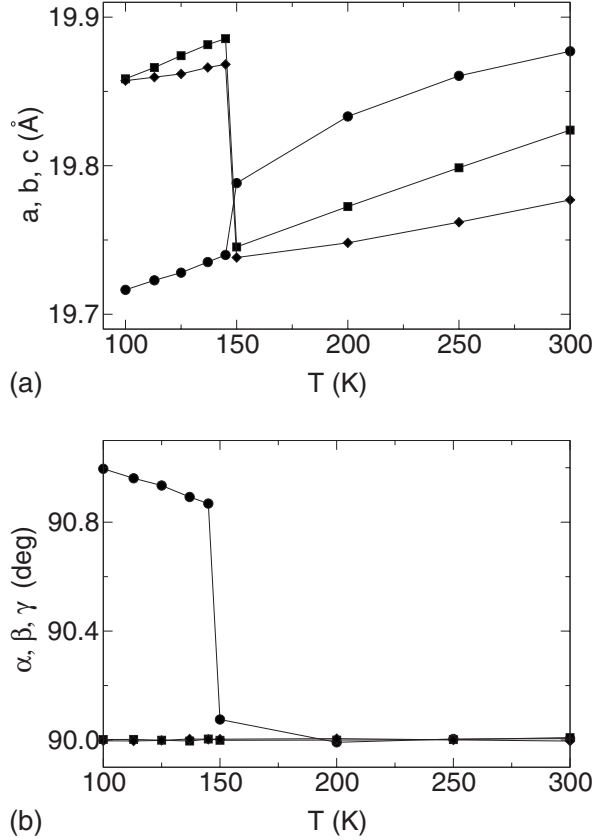

FIG. 4. Simulated monoclinic to orthorhombic transition of silicalite, BKS $^{\text {mod }}$ model: (a) Cell sides, shown for convenience of plotting as: $a+0.3 \AA(\square), b(\bullet), c+6.5 \AA(\diamond)$; (b) cell angles: $\alpha(\square), \beta(\bullet), \gamma(\bullet)$

mental adsorption enthalpies of water in silicalite vary over a wide range, $25.1-50.6 \mathrm{~kJ} \mathrm{~mol}^{-1}$, possibly reflecting varying amounts of defects, principally the aluminum content with its contingent hydroxyl groups. ${ }^{41,49,45,50,2}$ Most values of the enthalpies in pure silicalite are nonetheless below the enthalpy of vaporization of water, indicating hydrophobic behavior. The adsorption enthalpy also depends on the loading, due to interactions between water molecules. Bolis et al. ${ }^{51}$ compared adsorption of water in pure silica MFI and the hydroxylated form H-MFI (less than 15\% aluminum) and in the similar BEA and H-BEA zeolites (over 20\%). The adsorption enthalpy in the hydroxylated forms converged under saturation loading (about 24 molecules per unit cell at atmospheric pressure) to the vaporization enthalpy of bulk water. Maximum loading in pure MFI was only eight molecules per unit cell.

Figure 6(a) shows the distribution of adsorption energies of a single water molecule in silicalite, obtained by simulated annealing with the $\mathrm{BKS}^{\mathrm{mod}}$ force field. The figure summarizes 1000 quenches to $1 \mathrm{~K}$ after heating $10 \mathrm{ps}$ to $300 \mathrm{~K}$. To gain a perspective, the vaporization enthalpy of SPC/E water is $-41.5 \mathrm{~kJ} \mathrm{~mol}^{-1}$ (Ref. 39) (experimental value $\left.-44 \mathrm{~kJ} \mathrm{~mol}^{-1}\right) .{ }^{52}$ The low adsorption energies are thus consistent with a hydrophobic surface. Two adsorption energies are identifiable, corresponding to the green and blue adsorption sites in Fig. 6(b). The larger (average of $-39.8 \mathrm{~kJ} \mathrm{~mol}^{-1}$ ) corresponds to the compact cloud of sites shown in green, where water is adsorbed to the walls at the intersections of the straight and zigzag channels. Adsorption at this site mainly relies on a hydrogen bond with the host oxygen. Sites corresponding to the lower adsorption energy $\left(-21.5 \mathrm{~kJ} \mathrm{~mol}^{-1}\right)$, shown in blue in Fig. 6(b), are unspecific, with water lying either at the center of the channel intersections types or in either channel. Contrary to first impressions,

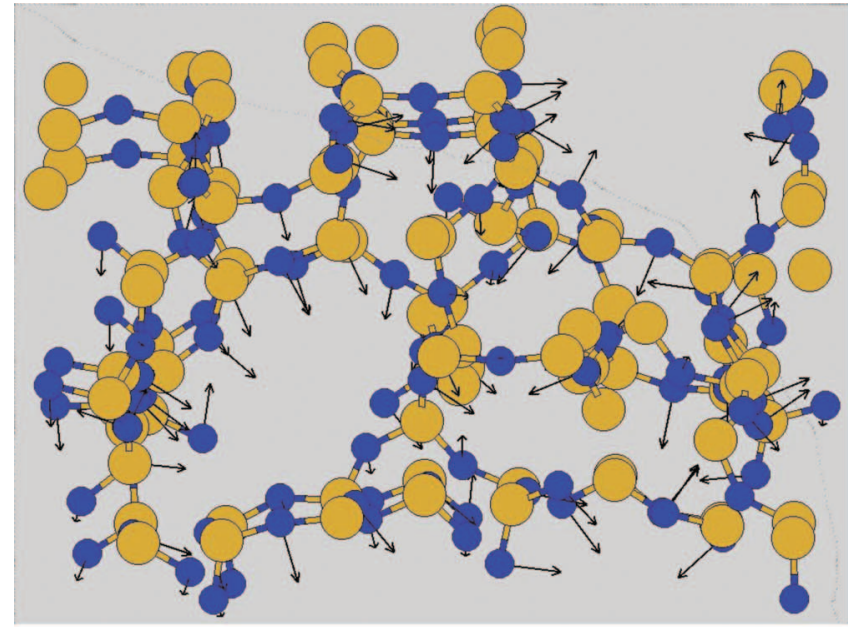

(a)

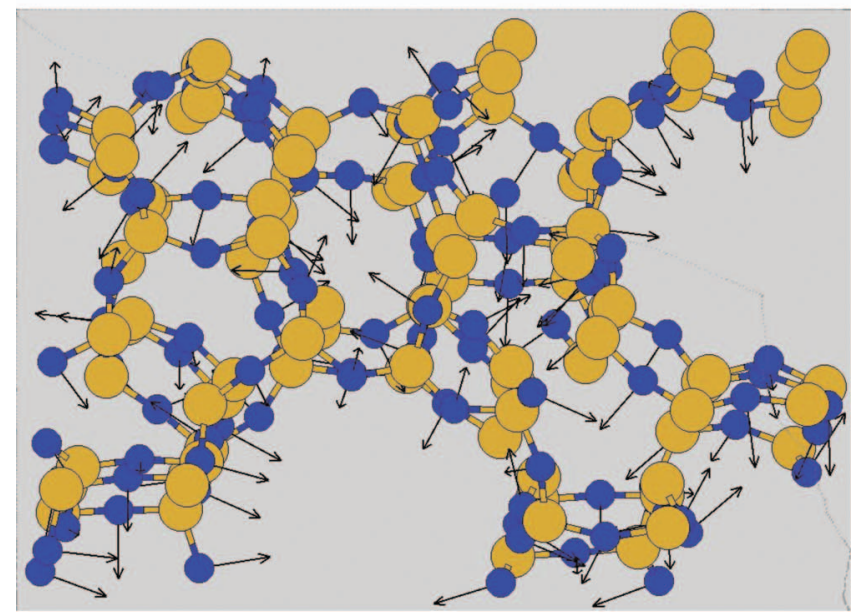

(b)

FIG. 5. Longest principal axes (arrows) of the most anisotropic oxygen thermal ellipsoids in the model silicalite (average over all atoms in the full simulation folded into one unit cell). (a) View parallel to $a$ along the zigzag channels; (b) view along the straight channels parallel to $b$.

the single specific adsorption site found in each channel intersection (green) is not an error. The apparent roughly cubic symmetry of the intersection is an illusion: it is broken by the ellipticity of the straight channels along $b$ intersecting circular channels zigzagging along $a$.

\section{Diffusion of water in silicalite}

There is a wide range of experimental molecular diffusion constants of water in silicalite, $1 \times 10^{-5}-4$ $\times 10^{-5} \mathrm{~cm}^{2} \mathrm{~s}^{-1}$ (Refs. 53, 54, and 31) compared to that in bulk water, $2.3 \times 10^{-5} \mathrm{~cm}^{2} \mathrm{~s}^{-1}, 38$ which similar to the adsorption energies probably reflects variable hydroxyl defects. Diffusion of individual water molecules in silicalite at room temperature was estimated from molecular dynamics runs with 288 molecules in $3 \times 3 \times 4$ unit cells. For comparison, the diffusion constant in bulk SPC/E water is 2.49 $\times 10^{-5} \mathrm{~cm}^{2} \mathrm{~s}^{-1}$ at $300 \mathrm{~K}^{55}$ In agreement with experiment, diffusion was found to be faster in the $(a, b)$ plane than in bulk water, and anisotropic. Figure 7 shows the mean squared displacements along $a, b$, and $c(T=300 \mathrm{~K}$, orthorhombic phase). The diffusion constants are $D_{a}=3.5, D_{b}$ 

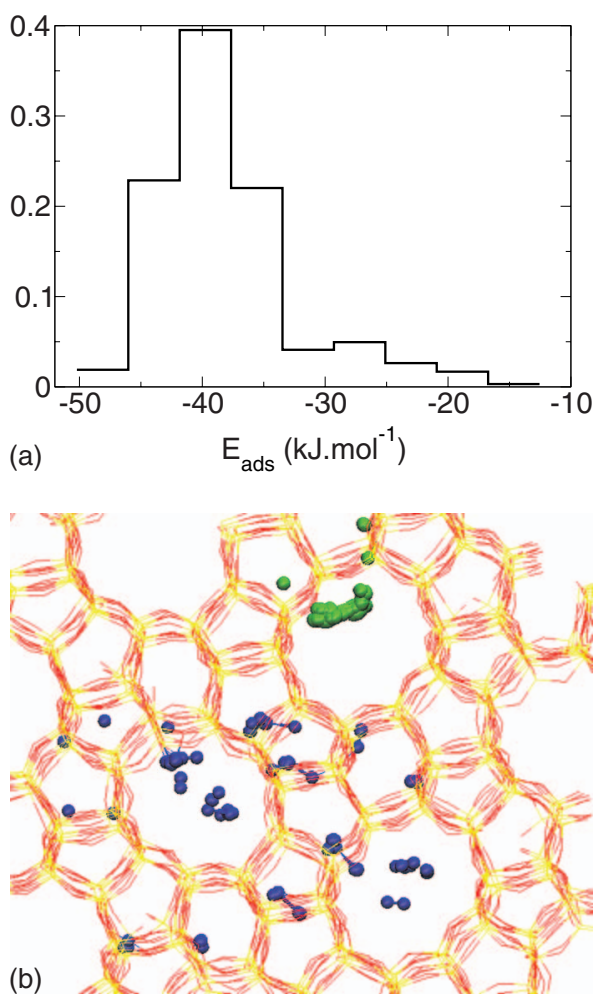

FIG. 6. (a) Adsorption energies of a single water molecule in silicalite, with the $\mathrm{BKS}^{\text {mod }}$ force field. (b) Adsorption sites corresponding to the energies $-39.8 \mathrm{~kJ} \mathrm{~mol}^{-1}$ (green), and $-21.5 \mathrm{~kJ} \mathrm{~mol}^{-1}$ (blue), viewed down the $b$ axis.

$=6.35$, and $D_{c}=0.9 \times 10^{-5} \mathrm{~cm}^{2} \mathrm{~s}^{-1}$. The zigzag channel segments in the $(a, c)$ plane make angles of $\alpha= \pm 34^{\circ}$ with the $a$ axis. If diffusion occurred at the same rate in the straight channels and in the segments of the zigzags, one would expect a ratio of the diffusion constants $D_{b} / D_{a} \approx 1 / \cos ^{2} \alpha$ $\approx 1.45$. The observed ratio, 1.82 , thus indicates that the intrinsic speed along either direction is about the same and that the apparent slower diffusion along $a$ is largely due to the zigzag paths followed along that direction.

By similar reasoning, diffusion one unit along $c$ involves two half zigzags in the $a, c$ plane, separated by a connecting $1 / 2$-unit passage along $b$, which should require a total time of the order of the sum of the individual times in each passage

$$
t_{c} \approx c^{2} / 2 D_{c} \approx \frac{(b / 2)^{2}}{2 D_{b}}+2 \frac{(a / 2)^{2}}{2 D_{a}} .
$$

Hence the expected value of $D_{c}$ should be

$$
D_{c} \approx \frac{c^{2}}{\left(b^{2} / 4+a^{2} / 2 \cos ^{2} \alpha\right)} D_{b} \approx 0.46 D_{b} .
$$

The actual value, about $0.14 D_{b}$, is thus considerably smaller. Examining Fig. 7, we observe that the reason is that the onset of regular diffusion along $c$ lags about 100 ps behind the onsets along $a$ and $b$. The value of the mean squared displacement along $b$ is then about $100 \AA^{2}$, or about $(b / 2)^{2}$. We therefore conclude that there is a barrier to switching between the straight and the zigzag channels, in agreement with the conclusions of other authors reached by different reasoning. ${ }^{52,53}$ The barrier actually corresponds to detrapping from the adsorption site [Fig. 6(b)]. Diffusion of water in our

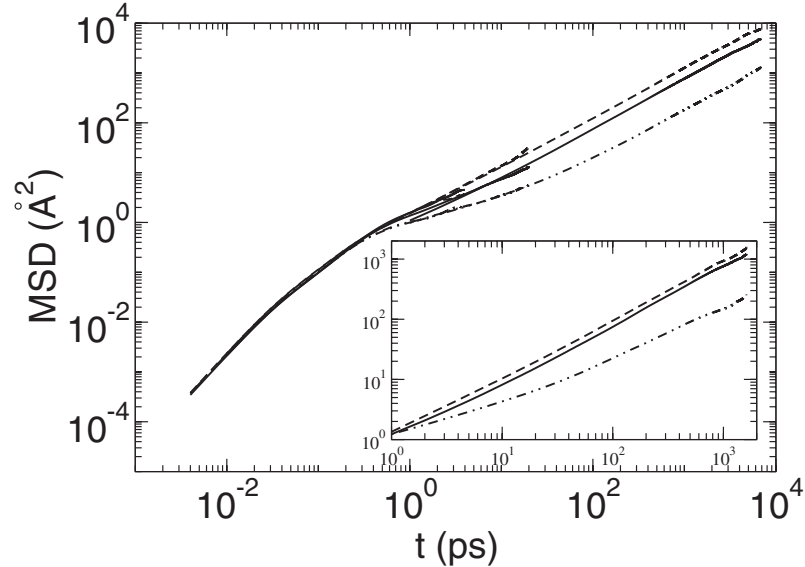

FIG. 7. Log-log plot of the mean squared displacements along $a$ (solid line), $b$ (dashed line), and $c$ (dot-dot-dashed line) of a SPC/E water molecule diffusing in silicalite (flexible $\mathrm{BKS}^{\text {mod }}$ model) at $300 \mathrm{~K}$. The inset shows the same mean squared displacements in silicalite with a frozen framework.

simulations occurs by sudden jumps between channel intersections, on time scales short compared to residence times at the intersections. Thus, on randomly sampling the water trajectories, one finds water $47 \%$ of the time at the intersections, which represent only $25 \%$ of the thermally accessible pore volume.

The inset in Fig. 7 shows mean squared displacements of water when the zeolite framework is frozen. Diffusion along $a$ is slightly faster, and that along $b$ significantly slower than with the flexible framework: $D_{a}=3.75$ and $D_{b}=4.65$ $\times 10^{-5} \mathrm{~cm}^{2} \mathrm{~s}^{-1}$. Movement along $c$ is subdiffusive in the rigid model. Flexibility of the framework, although found above to be limited, thus significantly influences the diffusion of water. Demontis et al., ${ }^{6}$ devised a measure of the switching of water molecules between channels

$$
\beta=\frac{c^{2} / D_{c}}{a^{2} / D_{a}+b^{2} / D_{b}} .
$$

For $\beta>1$, diffusion is preferentially in the same channel, whereas $\beta<1$ implies a tendency to switch channels. The $\mathrm{BKS}^{\text {mod }}$ model of silicalite yields $\beta=1.11$ in agreement with previous values $\beta=1.14$ (Ref. 32) and $\beta=1.20$. $^{6}$

\section{CONCLUSION}

The BKS force field for silica has been modified by reducing the partial charges to $q_{\mathrm{Si}}=+1.6, q_{\mathrm{O}}=-0.8$ and simultaneously adjusting the covalent bond potential wells. The new force field, adjusted with respect to $\alpha$-quartz, gives a fair description of the structural and elastic properties of other silica polymorphs, such as cristobalite and silicalite. The reduction in partial charges allows for realistic simulation of the weak physisorption and molecular diffusion of water in silicalite, while maintaining framework flexibility, in qualitative and fair quantitative agreement with its known hydrophobic properties. The new force field improves the description of the flexibility of silicalite, for which it reproduces the monoclinic to orthorhombic transition. Flexibility of the framework subtly affects the diffusion of water, with different effects in the three crystallographic directions. The 
new force field is expected to be useful for simulation of physisorption in zeolites, allowing for interplay between the adsorbed phase and the flexibility of the host frameworks. Extensions to include surface hydroxyl groups are in progress.

\section{ACKNOWLEDGMENTS}

Part of the simulations in this work were performed at the M3PEC regional supercomputing facility, Bordeaux 1 University. This work was supported by ANR Grant No. CIS-007-05 (NOSSI project).

${ }^{1}$ K. D. Hammonds, V. Heine, and M. T. Dove, J. Phys. Chem. B 102, 1759 (1998)

${ }^{2}$ G. Artioli, C. Lamberti, and G. L. Marra, Acta Crystallogr., Sect. B: Struct. Sci. 56, 2 (2000).

${ }^{3}$ H. van Koningsveld, F. Tuinstra, H. van Bekkum, and J. C. Jansen, Acta Crystallogr., Sect. B: Struct. Sci. 45, 423 (1989).

${ }^{4}$ R. Haberlandt and J. Kärger, Chem. Eng. J. 74, 15 (1999).

${ }^{5}$ B. Smit, D. Loyens, and G. Verbist, Faraday Discuss. 106, 93 (1997).

${ }^{6}$ P. Demontis, G. Stara, and G. B. Suffritti, J. Phys. Chem. B 107, 4426 (2003).

${ }^{7}$ N. E. R. Zimmermann, S. Jakobtorweihen, E. Beerdsen, B. Smit, and F. J. Keil, J. Phys. Chem. C 111, 17370 (2007).

${ }^{8}$ S. Tsuneyuki, M. Tsukade, H. Aoki, and Y. Matsui, Phys. Rev. Lett. 61, 869 (1988).

${ }^{9}$ B. W. H. van Beest, G. J. Kramer, and R. A. van Santen, Phys. Rev. Lett. 64, 1955 (1990).

${ }^{10}$ G. J. Kramer, N. P. Farragher, B. W. H. van Beest, and R. A. van Santen, Phys. Rev. B 43, 5068 (1991).

${ }^{11}$ J. Hill and J. Sauer, J. Phys. Chem. 98, 1238 (1994).

${ }^{12}$ D. M. Teter, G. V. Gibbs, M. B. Boisen, Jr., D. C. Allan, and M. P. Teter, Phys. Rev. B 52, 8064 (1995).

${ }^{13}$ R. A. Jackson and C. R. A. Catlow, Mol. Simul. 1, 207 (1988).

${ }^{14}$ M. Matsui, Phys. Chem. Miner. 23, 345 (1996).

${ }^{15}$ G. Sastre, D. W. Lewis, and C. R. A. Catlow, J. Phys. Chem. 100, 6722 (1996).

${ }^{16}$ E. de Vos Burchart, H. van Bekkum, B. van Graaf, and E. T. C. Voigt, J. Chem. Soc., Faraday Trans. 88, 2761 (1992).

${ }^{17}$ J. D. Gale and N. Henson, J. Chem. Soc., Faraday Trans. 90, 3175 (1994)

${ }^{18}$ M. Praprotnik, S. Hočevar, M. Hodošček, M. Penca, and D. Janežič, J. Comput. Chem. 29, 122 (2007).

${ }^{19}$ K. P. Schröder, J. Sauer, M. Leslie, C. R. A. Catlow, and J. M. Thomas, Chem. Phys. Lett. 188, 320 (1992).

${ }^{20}$ J. C. White and A. C. Hess, J. Phys. Chem. 97, 8703 (1993).

${ }^{21}$ A. V. Larin and D. P. Vercauteren, Int. J. Inorg. Mater. 1, 201 (1999).

${ }^{22}$ R. Dovesi, C. Pisani, C. Roetti, and B. Silvi, J. Chem. Phys. 86, 6967 (1987).

${ }^{23}$ N. Desbiens, A. Boutin, and I. Demachy, J. Phys. Chem. B 109, 24071 (2005).

${ }^{24}$ V. Saunders, R. Dovesi, C. Roetti, R. Orlando, C. Zicovich-Wilson, N. Harrison, K. Doll, B. Civalleri, I. Bush, P. D'Arco, and M. Llunell, Crys- tal 06 User Manual (Universit di Torino, Torino, 1996).

${ }^{25}$ C. Pisani, R. Dovesi, and C. Roetti, Hartree-Fock Ab Initio Treatment of Crystalline Solids, Lecture Notes in Chemistry Vol. 48 (Springer-Verlag, Heidelberg, 1988).

${ }^{26}$ P.-A. Cazade, Ph.D. thesis, Université de Pau, 2008.

${ }^{27}$ S. Jost, S. Fritzsche, and R. Haberlandt, Chem. Phys. Lett. 279, 385 (1997).

${ }^{28}$ A. H. de Vries, P. Sherwood, S. J. Collins, A. M. Rugby, M. Rigutto, and G. J. Kramer, J. Phys. Chem. 103, 6133 (1999).

${ }^{29}$ N. Desbiens, I. Demachy, A. H. Fuchs, H. Kirsch-Rodeschini, M. Soulard, and J. Patarin, Angew. Chem., Int. Ed. 44, 5310 (2005).

${ }^{30}$ C. E. Ramachandran, S. Chempath, L. J. Broadbelt, and R. Q. Snurr, Microporous Mesoporous Mater. 90, 293 (2006).

${ }^{31}$ C. Bussai, S. Vasenkof, H. Liu, W. Böhlmann, S. Fritzsche, S. Hannongbua, R. Haberlandt, and R. Kärger, Appl. Catal., A 232, 59 (2002).

${ }^{32}$ M. Fleys, R. W. Thompson, and J. C. MacDonald, J. Phys. Chem. B 108, 12197 (2004).

${ }^{33}$ D. Eisenberg and W. Kauzmann, The Structure and Properties of Water (Clarendon, Oxford, 1969).

${ }^{34}$ K. Krynicki, C. Green, and D. Sawyer, Faraday Discuss. Chem. Soc. 66, 199 (1978).

${ }^{35}$ N. A. McDonald and W. L. Jorgensen, J. Phys. Chem. B 102, 8049 (1998), and references therein.

${ }^{36}$ M. Benot, S. Ispas, P. Jund, and R. Jullien, Eur. Phys. J. B 13, 631 (2000).

${ }^{37}$ J. D. Gale and A. L. Rohl, Mol. Simul. 29, 291 (2003).

${ }^{38}$ H. J. C. Berendsen, J. R. Grigera, and T. P. Straatsma, J. Phys. Chem. 91, 6269 (1987).

${ }^{39}$ P. G. Kusalik and I. M. Svishchev, Science 265, 1219 (1994).

${ }^{40}$ A. I. Kitaigorodskii, J. Chim. Phys. Phys.-Chim. Biol. 63, 6 (1966).

${ }^{41}$ G. A. Lager, J. D. Jorgensen, and F. J. Rotella, J. Appl. Phys. 53, 6751 (1982).

${ }^{42}$ H. J. McSkimin, P. Andreatch, Jr., and R. N. Thurston, J. Appl. Phys. 36, 1624 (1965).

${ }^{43}$ T. R. Forester and W. Smith, The DL_POLY_2.0 User Manual (Daresbury, Warrington, 2007).

${ }^{44}$ H. J. C. Berendsen, J. P. M. Postma, W. F. van Gunsteren, A. DiNola, and J. R. Haak, J. Chem. Phys. 81, 3684 (1984).

${ }^{45}$ D. R. Peacor, Z. Kristallogr. 138, 274 (1973).

${ }^{46}$ H. Kimizuka and H. Kaburaki, Phys. Status Solidi B 242, 607 (2005).

${ }^{47}$ H. van Koningsveld, Colloids Surf., A 46, 731 (1990).

${ }^{48}$ L. T. Zhuravlev, Colloids Surf., A 173, 1 (2000).

${ }^{49}$ K. Kihara, Eur. J. Mineral. 2, 63 (1990).

${ }^{50}$ H. van Koningsveld, J. C. Jansen, and H. van Bekkum, Zeolites 10, 235 (1990).

${ }^{51}$ V. Bolis and C. Burso, J. Phys. Chem. B 110, 14849 (2006).

${ }^{52}$ P. J. Linstrom and W. G. Mallard, NIST Standard Reference Database Number 69 (National Institute of Standards and Technology, Gaithersburg, 2005).

${ }^{53}$ J. Caro, M. Bülow, J. Richter-Mendau, J. Kärger, M. Hunger, D. Freude, and L. V. C. Rees, J. Chem. Soc., Faraday Trans. 83, 1843 (1987).

${ }^{54}$ J. Caro, S. Hocevar, J. Kärger, and L. Rieckert, Zeolites 6, 213 (1986).

${ }^{55}$ M. W. Mahoney and W. L. Jorgensen, J. Chem. Phys. 114, 363 (2001).

${ }^{56}$ J. J. Pluth, J. V. Smith, and J. Faber, Jr., J. Appl. Phys. 57, 1045 (1985).

${ }^{57}$ A. Yeganeh-Haeri, D. J. Weidner, and J. B. Parise, Science 257, 650 (1992). 